\title{
Representações sociais de enfermeiros sobre a religiosidade ao cuidar de pacientes em processo de morte
}

Social representations of nurses about religiosity while caring for patients in the dying process Representaciones sociales de enfermeros sobre religiosidad al cuidar de pacientes en proceso de muerte

\author{
Fátima Maria da Silva Abrão', Amanda Regina da Silva Góis', Marcia Santos Brasil de Souza', \\ Raquell Alves de Araujo', Charmênia Maria Braga Cartaxo", Denize Cristina de Oliveira"II \\ ' Universidade de Pernambuco, Faculdade de Enfermagem Nossa Senhora das Graças. Recife - PE, Brasil. \\ "Universidade de Pernambuco, Instituto de Ciências Biológicas. Recife - PE, Brasil. \\ II' Universidade do Estado do Rio de Janeiro, Faculdade de Enfermagem. Rio de Janeiro - RJ, Brasil.
}

\author{
Submissão: 19-04-2012 Aprovação: 04-09-2013
}

\section{RESUMO}

Estudo qualitativo, ancorado na Teoria das Representações Sociais a partir do pensamento de Jodelet, realizado em uma Unidade de Terapia Intensiva e Oncologia de um hospital universitário. Objetivou-se compreender as representações sociais dos enfermeiros acerca da religiosidade ao cuidar de pacientes em processo de morte. Os dados foram coletados de maio a agosto de 2010, utilizando a técnica de Análise de Conteúdo de Bardin. As representações da religiosidade inseridas na prática do cuidar de pacientes em processo de morte valorizam as crenças dos profissionais sobre a morte, seu significado permitindo elaborar mecanismos de enfrentamento. Considera-se que a tomada de consciência se dará através da compreensão da realidade e da inserção da temática na discussão da qualidade da saúde e da capacitação dos profissionais.

Descritores: Enfermagem Oncológica; Cuidados Críticos; Atitude Frente à Morte; Unidades de Terapia Intensiva.

ABSTRACT
This is a qualitative study, anchored in the Theory of Social Representation and Jodelet thoughts, realized in an Intensive Care and Oncology Unit of a university hospital. The objective was to understand the social representations of nurses on religiosity while caring for dying patients. The data was collected between 2010May and August, using the technique of Content Analysis of Bardin. The religiosity representations inserted in the caring practice for dying patients, value professional's beliefs about death, its meaning allowing for the development of coping mechanisms. It is considered that the awareness will occur through the understanding of reality and introducing the theme in the discussion of the quality of health and training of professionals.

Key words: Oncology Nursing; Critical Care; Attitude to Death; Intensive Care Units.

\section{RESUMEN}

Estudio cualitativo, anclado en la teoría de las representaciones sociales y en el pensamiento de Jodelet, realizado en una Unidad de Cuidados Intensivos y Oncología de un hospital universitario. El objetivo fue comprender las representaciones sociales de los enfermeros acerca de la religiosidad durante la atención a pacientes en proceso de muerte. Los datos, recogidos de mayo hasta agosto de 2010, fueran analizados según la Técnica de Análisis de Contenido de Bardin. Las representaciones de la religiosidad insertadas en la práctica de atención de pacientes en proceso de morir, valorizan las creencias de los profesionales acerca de la muerte, y su significado permite desarrollar mecanismos de afrontamiento. Se concluye que la toma de conciencia ocurre través de la comprensión de la realidad e de la introducción del tema en la discusión de la cualidad de la salud y en la formación de los profesionales.

Palabras clave: Enfermería de Oncología; Cuidados Críticos; Actitud Frente a la Muerte; Unidades de Cuidados Intensivos. 


\section{INTRODUÇÃO}

O presente estudo teve como objeto a religiosidade no cuidar do paciente em processo de morte em Unidade Oncológica e de Terapia Intensiva. Como sabido, nesses cenários a morte é uma realidade que se apresenta com maior frequência do que em outras unidades hospitalares. Considera-se relevante essa temática analisada sob a ótica da teoria das representações sociais, tendo em vista que o ser enfermeiro é um indivíduo que recebe múltiplas influências sociais, culturais, psicológicas e espirituais e tende a aplicá-las no cotidiano profissional.

O enfermeiro é reconhecido como aquele que cuida, porém, atualmente, o descuido e o descaso têm se mostrado mais evidentes, o que revela um gradual abandono no aperfeiçoamento da compreensão do cuidar, sobretudo no enfrentamento do processo de morte, o que acaba por demonstrar o despreparo de muitos profissionais e a deficiência curricular dos cursos de enfermagem ${ }^{(1-2)}$. Isso se deve às mudanças na relação entre o homem e a concepção do processo de morte no percurso histórico-cultural vivenciado também na profissionalização da enfermagem.

Tal percurso histórico-cultural, expresso na literatura, revela que ainda na Idade Média a morte era compreendida como um acontecimento natural, domiciliar e familiar, com amplo significado religioso, sendo esta e o adoecimento atrelados à vontade divina. No entanto, sabe-se que a partir do século $\mathrm{XX}$, iniciou-se a luta contra a morte dos pacientes, fato que se deve aos avanços tecnológicos, bem como ao afastamento do pensamento religioso ${ }^{(3)}$. Após a década de 1930, o número de óbitos em hospitais começou a crescer, de modo que, na atualidade, a morte acontece prioritariamente nos hospitais e, por conseguinte, mais próxima do trabalho dos enfermeiros ${ }^{(3-4)}$. Isso pode ser devido às mudanças de perspectiva social atreladas ao pensamento capitalista em expansão, que valorizam as relações trabalhistas e da produtividade humana ${ }^{(5)}$.

Nessas relações há uma preocupação sobre o modo como esse profissional lida, diariamente, com a morte e com as diferentes concepções religiosas atribuídas a ela. Tanto nas Unidades Oncológicas quanto nas Unidades de Terapia Intensiva (UTI), a compreensão acerca da religiosidade no cuidar do paciente em processo de morte passa a ser relevante. No entanto, é a iminência da falência orgânica e o desejo humano de alcançar imortalidade que aguçam a reflexão sobre a vigente presença da negação da morte nas falas dos profissionais enfermeiros na sociedade atual, revelando o mais antigo paradoxo existencial: o medo da morte ${ }^{(6)}$.

As temáticas da morte e da religiosidade têm sido pouco exploradas pelos profissionais, alunos e instituições de ensino, e isso se reflete na preocupação de que "talvez o maior obstáculo a enfrentar quando se procura compreender a morte seja o fato de que é impossível para o inconsciente imaginar um fim para sua própria vida"(7) e, para isso, os enfermeiros necessitam compreender o simbolismo e o significado do que para eles representa a morte em seu cotidiano profissional.

Como se apresenta para os enfermeiros de Unidades de Oncologia e de Terapia Intensiva a religiosidade ao cuidar do paciente em processo de morte? O presente estudo teve como objetivo compreender as representações sociais dos enfermeiros acerca da religiosidade ao cuidar de pacientes em processo de morte.

\section{MÉTODO}

Trata-se de um estudo de campo, com abordagem qualitativa que utilizou o referencial teórico e metodológico da Teoria das Representações Sociais segundo o pensamento de Jodelet, desenvolvido no âmbito da Psicologia Social que propõe a reflexão sobre a realidade e suas implicações. Apoiados nesta autora, toma-se como base valores e ideias compartilhadas pelo grupo social, formado nesta pesquisa por enfermeiros de Unidade de Terapia Intensiva e Oncologia de um hospital universitário da cidade do Recife, Pernambuco, Brasil no qual estão inseridos, sendo esses valores os responsáveis por reger as condutas desejáveis ou admitidas ${ }^{(3,8)}$.

A população do estudo constituiu-se de 40 enfermeiros, sendo 21 da Oncologia e 19 da UTI, tendo sido a amostra de 20 enfermeiros, sendo 10 de cada setor acima descrito. Após assinatura do Termo de Consentimento Livre e Esclarecido, coletaram-se os dados através de um roteiro de entrevista semiestruturado, com perguntas abertas referentes às representações da religiosidade no cuidar do paciente em processo de morte. Como critérios de inclusão, considerou-se: ser enfermeiro, servidor público em escala de plantão, pertencente às unidades de internamento de oncologia (Adulto, pediátrico e quimioterapia) e da UTI (Geral, pediátrica e doenças infecciosas e parasitárias - DIP) e ter aceitado participar do estudo, assinando o TCLE (Termo de Consentimento Livre Esclarecido). Os enfermeiros em férias, licença maternidade, afastamento por licença médica ou para estudo de aperfeiçoamento acadêmico e em regime de plantões extras no período da coleta de dados, bem como aqueles que não demonstraram interesse em participar do estudo ou não concordaram em assinar o TCLE, inseriram-se nos critérios de exclusão.

Os dados foram coletados pelos pesquisadores deste estudo entre os meses de maio a agosto de 2010. As entrevistas duraram entre 10 e 120 minutos. Após serem gravadas e transcritas, considerou-se o sigilo dos sujeitos nomeando-os com a seguinte codificação: categoria profissional, número sequencial e unidade de trabalho. Sendo Enf designado para categoria Enfermeiro, e os números sequenciais sendo dispostos em algarismos arábicos, por ordem de coleta dos dados em cada setor.

Posteriormente, utilizou-se a análise de conteúdo temática que, segundo $\operatorname{Bardin}^{(9)}$, representa um conjunto de técnicas de análise das comunicações que visam à obtenção, por procedimentos sistemáticos e objetivos de descrição do conteúdo das mensagens, de indicadores que permitam a inferência de conhecimentos relativos às condições de produção e de recepção dessas mensagens através da categorização dos depoimentos. Isso revela dois pólos metodológicos, a rigorosidade e a necessidade de ir além das aparências sob duas orientações que, ao mesmo tempo em que se confrontam, se complementam: a verificação prudente ou a interpretação brilhante. 
Procedeu-se à organização das falas, tendo emergido as seguintes categorias: 1) Passagem para uma nova vida; 2) Processo Natural e Fisiológico; 3) Alívio do Sofrimento; 4) Preces, Rezas, Orações e Consolo; 5) Respeitar e Incentivar a Religiosidade do paciente e da família; 6) Acolhimento e Humanização; 7) Distanciamento na Assistência Profissional; 8) Capacitação e Aperfeiçoamento; 9) Conforto Espiritual e Controle Emocional; 10) Tranquilidade e Calma; 11) Frustração e Sofrimento. Todos compreendidos, no presente estudo, através de cinco Eixos Temáticos, de modo a contribuir para a sistematização da análise metodológica. Sendo estes: A) Representações pessoais, profissionais e religiosas do enfermeiro acerca do processo de morte; B) Representações da religiosidade no cuidado de pacientes terminais e/ou graves; C) Representação da relação ideal entre Paciente-Enfermeiro-Família no processo de morte; D) Representações do enfermeiro acerca dos mecanismos de enfrentamento do processo de morte; E) Representações e experiências dos enfermeiros frente ao processo de morte.

No tocante aos aspectos éticos, respeitaram-se os princípios em conformidade com a Resolução CNS nº 466/2012 do Ministério da Saúde, sobre Diretrizes e Normas Regulamentadoras de Pesquisa envolvendo Seres Humanos. Para realização da pesquisa, obtiveram-se duas aprovações do Comitê de Ética em Pesquisa: uma para o estudo em Oncologia através do projeto de iniciação científica intitulado Cotidiano Profissional: como os enfermeiros lidam com a morte e a religiosidade em seu processo de cuidar? E outra, para o estudo em UTI, denominado Processo de Cuidar: como os enfermeiros de Unidade de Terapia Intensiva lidam com a morte e a religiosidade em seu cotidiano profissional? Tendo sido aprovados e registrados com o CAAE: 0060.0.106.000-09 e CAAE: 0084.0.106.000-10, respectivamente.

Os dados utilizados no presente estudo são oriundos dos projetos de iniciação científica mencionados anteriormente, e financiados pelo Conselho Nacional de Desenvolvimento Científico e Tecnológico (CNPq). Os dados foram obtidos no período entre agosto de 2009 e agosto de 2011.

\section{RESULTADOS E DISCUSSÃO}

Nos cenários da pesquisa em Unidade de Oncologia e de Terapia Intensiva foram verificados elementos que revelam a contribuição da religiosidade no cuidar, como principalmente a presença de uma capela no hospital. Outras referências religiosas podem ser percebidas na configuração do espaço físico com a presença de elementos como imagens, quadros de personagens bíblicos, crucifixos, terços e literatura sacra.

A importância da presença desses objetos foi reafirmada em estudos anteriores, pois estes representam um elo entre o alívio e a dor, a vida e a morte, a fé, o conforto e a esperança ${ }^{(10)}$. E a partir da análise das falas presentes no estudo, foi possível elaborar os cinco Eixos Temáticos, também entendidos como esquemas figurativos, uma vez que encerram aspectos dimensionais da informação, atitude e campo representacional ${ }^{(8)}$.

\section{A. Representações pessoais, profissionais e religiosas do enfermeiro acerca do processo de morte}

A motivação para cuidar dos enfermos situou-se inicialmente no ato de solidariedade humana vinculado à religiosidade $\mathrm{e}$ à abnegação ${ }^{(11)}$. Contudo, mantem-se presente no imaginário do profissional, através de práticas e crenças, a religiosidade vinculada à assistência e ao acesso aos serviços de saúde, seja através de financiamentos filantrópicos por meio de doações de fiéis e sociedade civil, da presença de capelas, igrejas e salas de oração ou da prática de visitas regulares aos locais de internamento de figuras representativas de instituições religiosas.

As representações dos enfermeiros, quanto ao processo de morte, permitem a elaboração de conceitos relevantes para o cuidado atribuídos e formulados sob a influência social, cultural e histórica ${ }^{(8)}$. Os conceitos são concebidos integralmente sob o ponto de vista pessoal, profissional e religioso, e por vezes dicotomizados, evidenciando a multiplicidade inerente ao processo de morte para o ser enfermeiro, sobretudo quando se sobrepõe a influência religiosa na construção destes conceitos fazendo emergir a presente categoria: passagem para uma nova vida, como demonstram as falas abaixo:

A morte? É, a gente, no dia a dia, sabe que chega o momento em que nós temos que partir para outra vida, entendeu? [...] a morte seria a passagem dessa vida para outra vida eterna. (Enf. 9 - UTI).

A morte para mim?Bom, é a passagem desta vida para vida eterna, assim, pelo que eu saiba das religiões que eu tive acesso; para os cristãos, é uma passagem, (Enf. 16 - Oncologia).

A influência da religiosidade nas representações acerca do processo de morte está presente nas falas dos enfermeiros. Essa presença é reafirmada em estudo realizado com estudantes de enfermagem, que apresenta a partir do episódio da morte, como elemento interveniente às crenças, a convicção de que a fé religiosa influencia a capacidade de enfrentamento de situações envolvendo a morte e o morrer ${ }^{(12)}$. Outro estudo realizado com enfermeiros e demais profissionais de saúde, apresenta a religiosidade como parte da estrutura da representação, desvelando a morte como: "fim, passagem, mistério, perda, sono, corte, retorno, experiência macabra, experiência natural, experiência abstrata, experiência triste e encontro com a verdade ${ }^{(19)}$.

Essas definições e conceitos aproximam-se dos resultados encontrados no presente estudo, revelando a influência religiosa na concepção do enfermeiro sobre o processo de morte, a partir da atuação do divino e do místico, permitindo a passagem para uma nova vida após a morte do corpo físico.

Contudo, a teoria das representações sociais, neste estudo, revela que o processo de morte compreendido e então enfrentado pelo enfermeiro constitui relação de dependência com o sentido que eles dão à vida. Esta por si só apresenta desafios e a relação de dependência perpassa no sentido de se conhecer a si mesmo, e saber que as escolhas mais difíceis serão as mais elevadas e também como se ter consciência que a morte não 
existe, e que nunca estamos sozinhos na passagem ${ }^{(7)}$. A morte pode representar, para um indivíduo em um contexto sociocultural e religioso, o fim do corpo, alma e espírito, no sentido de que a vida não transcende, ou ainda o encontro com uma fonte de vida, que pode ser mística e eterna ou até mesmo com o próprio Deus. As concepções e definições da morte contribuem tanto nas ações e escolhas pessoais, como nos hábitos relacionados às construções para a realidade, diante do fato de que se criam representações, porque se necessita de informações sobre o mundo à volta para o ajuste do comportamento, a fim de solucionar problemas oriundos das relações com objetos, pessoas, acontecimentos ou idéias ${ }^{(8)}$.

Nesse sentido, cuidar do indivíduo que está morrendo ou sofrendo consiste em internalizar uma compreensão esperançosa da morte, cultivar o desejo humano do infinito, sentimentos estes expressos na religiosidade, impedindo que ele se identifique com objetos finitos e sofra com a possibilidade de morte associada ao câncer e ao internamento em Unidades de Terapia Intensiva ${ }^{(13)}$.

Em algumas falas observa-se a representação do enfermeiro quanto aos conceitos de morte, como sendo fundada em concepções apenas biológicas e tecnicistas com base em critérios fisiológicos, como a utilização de protocolos de morte encefálica em UTI, ou seja, de perda irreversível das funções do Tronco Cerebral, ainda dúbios e confusos na aplicabilidade na prática profissional neste serviço, embora emergentes nas falas como representação da morte, apreendida na categoria: processo natural e fisiológico, evidenciada nas falas abaixo:

Seria a ausência de vida. Assim[...]Os batimentos cessaram, o cérebro foi embora e o paciente morreu, não tá mais lá, não tem mais sinais vitais. (Enf. 3 - UTI).

Morte para mim assim é um processo natural, todo mundo nasce, cresce, se reproduz e morre, é um processo natural é um processo que vai acontecer para mim, para vocês e para todo mundo. (Enf. 8 - UTI).

Tradicionalmente, a definição da morte fazia referência ao instante do cessamento dos batimentos cardíacos. Essa definição tornou-se obsoleta, e hoje, a morte é compreendida como um processo biopsicossocial, um fenômeno progressivo e não mais como um momento, ou evento analisado separadamente ${ }^{(14)}$. A morte como evento isolado é diagnosticada pelo profissional médico através de exame físico, aplicação da escala de Glasgow e exames complementares. A morte, como fenômeno natural, faz parte do ciclo de vida de todo ser vivo.

Acredita-se que o enfermeiro através de suas concepções, apreendidas na academia, sobre as questões decorrentes do ciclo de vida, se aproprie prioritariamente da representação biológica da morte, devido à grande carga horária curricular associada a disciplinas com aproximação e fundamentação teórica essencialmente biológica em detrimento das outras com valorização das esferas psicossociais. As Diretrizes Curriculares Nacionais do curso de Graduação em Enfermagem, instituídas pela Resolução CNE/CES no 3, de 7 de novembro de 2001, apontam para atenção à saúde identificando as dimensões biopsicossociais dos determinantes do processo de saúde-doença. A Tanatologia, como um tema transversal na matriz curricular, precisa ser abordada com maior ênfase no ensino de graduação.

Entretanto, a morte em Unidades Oncológicas e de Terapia Intensiva representa também, em muitos casos, um alívio do sofrimento para pacientes e familiares, bem como para o próprio profissional enfermeiro que cuida diariamente desses pacientes. As compreensões presentes nas falas dos enfermeiros retomam a concepção da morte como um fim do sofrimento e possibilidade de recomeço longe dos sentimentos negativos, em uma nova esfera que remete à influência religiosa na prática profissional. Assim emerge a seguinte categoria: alívio do sofrimento.

Para gente assim, a morte é até assim[...]'terminou o sofrimento', porque assim, aqui muitos pacientes sofrem muito, a morte é até assim, um descanso realmente! Ele pára de sofrer [...]. Então, quando ele morre, realmente é um descanso, porque o sofrimento daquele paciente foi embora para ele, para família e para mim. (Enf. 10 - Oncologia).

O processo de morte acarreta uma grande carga de sofrimento relacionada à dor física decorrente dos sinais e sintomas característicos da doença e de procedimentos invasivos realizados durante o internamento, bem como reações e ações adversas à terapêutica medicamentosa, sofrimento psíquico relacionado à distância do ambiente familiar ${ }^{(3)}$.

O enfermeiro vivencia o processo de morte e, como mecanismo de defesa, a morte se apresenta como o fim do sofrimento, ou alívio para o paciente, familiares e, sobretudo, da equipe de enfermagem. Fica evidenciado, portanto, o reflexo da esperança religiosa nas concepções compreendidas no âmbito das representações sociais através de conjuntos de conhecimentos e crenças elaboradas coletivamente ${ }^{(8)}$. Analogamente, num estudo realizado com trabalhadores de enfermagem, ficou claro que estes preferem utilizar estratégias coletivas de defesa, para enfrentar a dor ocasionada pela morte dos pacientes ${ }^{(3)}$.

\section{B. Representações da religiosidade no cuidar de pacientes terminais e/ou graves}

A religiosidade está presente no cuidar do paciente em processo de morte, pois a formação da enfermagem como profissão tem sido extremamente atrelada à religiosidade no decorrer da história(15). Emerge, então, a seguinte categoria: preces, rezas, orações e consolo, evidenciada nas falas que revelam a contribuição dos elementos da religiosidade do próprio enfermeiro no cuidar, pois alguns enfermeiros rezam e oram pelos pacientes e por seus familiares enquanto cuidam deles na oncologia e na UTI, como pode ser observado:

Eu faço uma oração, eu rezo, não encarando esse processo como sendo algo material, biológico, eu acho que tem um prolongamento na vida. (Enf. 1- UTI).

A gente procura amenizar [...], tenta consolar, tenta estar presente de alguma forma, até no cuidado, dar um abraço, tentar acalmar[...]. Como profissional, minha visão é 
totalmente cristã, eu tento passar um pouco disso, a questão cristã mesmo de consolo que só Jesus pode dar. (Enf. 11- Oncologia).

A religiosidade tem um significado importante para a humanidade, assim sendo, as atividades espirituais e religiosas podem ser agregadas às terapias e tratamentos realizados pela enfermagem, embora novas pesquisas na área ainda precisem ser implementadas, com o intuito de fundamentar a prática já encontrada comumente nos serviços, corroborando com alguns autores $^{(16)}$ que revelam que os recursos religiosos de orações, promessas, peregrinações, exercícios ascéticos e ações rituais são constantemente utilizados em situações de enfrentamento.

Ao compreender que a religiosidade faz parte do cuidado, alguns enfermeiros permitiram a apreensão da seguinte categoria: respeitar e incentivar a religiosidade do paciente e da família, observada nas falas de modo a valorizar e evidenciar as crenças do paciente e da família no cuidar de modo a expressar as suas crenças pessoais em segundo plano neste momento $^{(5)}$, como evidenciam as falas abaixo:

Assim, alguns deles (pacientes) se pegam muito mais à religiosidade, [...] então eu preciso apoiar o que deixa o paciente mais confortável. Eu digo ao paciente tenha fé, tenha fé! Porque até isso influi. (Enf. 8 - UTI).

Respeito sempre, respeitar a religiosidade do paciente, a individualidade de cada um. (Enf. 10 - Oncologia).

De uma forma geral, minha impressão pessoal é que a gente tem que deixar de lado nossa forma religiosa e respeitar a crença de cada família [...] (Enf. 5- UTI).

Desta forma, reafirma-se que a religiosidade torna-se importante para a maior parte dos pacientes, por isso os profissionais de saúde precisam conhecer e valorizar as crenças religiosas, uma vez que, para compreender a integralidade do cuidar, faz-se necessário inserir o suporte espiritual e/ou religioso $^{(8-16)}$ de modo a tornar o paciente e seus familiares mais confiantes em relação ao tratamento.

\section{Representações da relação ideal entre Paciente-Enfer- meiro-Família no processo de morte.}

A capacidade representacional desse tema do cotidiano do enfermeiro, no que diz respeito à relação entre a tríade Paciente-Enfermeiro-Família, no que se refere ao processo de morte, de modo a torná-la um momento mais brando, evidencia a categoria Acolhimento e Humanização nas seguintes falas:

Eu acho que não só a enfermagem, mas todos da equipe, para o paciente e para a família é sempre ter um bom acoIhimento, a humanização [...] para dar uma noticia de óbito [...]. Tornar a coisa um pouco mais humana. (Enf. 1 - UTI).

Eu particularmente acredito que a equipe, assim... [pausa] quanto mais dedicado, mais comprometido, tentando apoiar mais este paciente, a família para dar um final de vida menos doloroso possível [...] a gente tenta dar o maior suporte possível, levar um sorriso [...]. (Enf. 12 - Oncologia).

Sabe-se que a humanização no cuidar insere-se através da Política Nacional de Humanização, que busca a valorização dos diferentes sujeitos implicados no cuidar, desde usuários e trabalhadores, aos gestores, estabelecendo vínculos solidários e de participação coletiva no processo, além de incorporar condutas acolhedoras, pois o acolhimento apresenta-se como elemento essencial nessa política de humanização, sobretudo frente ao processo de morte, momento ímpar da condição humana. Neste âmbito, outros enfermeiros da pesquisa reforçam a construção da presente categoria, especificando elementos próprios da humanização e do acolhimento, como ainda pode ser evidenciado nas seguintes falas:

Acho que tem que ter diálogo e a gente tem que parar e escutar o paciente, mesmo na fase final, ele ainda tem coisas que quer Ihe dizer, tanto [...]. (Enf. 14-Oncologia)

Conversar com o paciente, mesmo quando achar que ele não tá mais ouvindo ou entendendo. (Enf. 1- UTI).

A comunicação e escuta ativas constituem procedimentos indissociáveis do cuidar humanizado e, portanto, do acolhimento. Neste contexto, as habilidades de comunicação para abordar o processo de morte são um instrumento necessário que viabiliza ao profissional identificar em qual das cinco fases do processo (Negação, Raiva, Barganha, Depressão e Aceitação) o paciente se encontra, e assim, auxiliar de forma integral na sua assistência ${ }^{(7)}$.

A comunicação se manifesta nas relações entre paciente, enfermeiro e família sob diversas formas, podendo ser verbalizada ou não. $\mathrm{O}$ enfermeiro precisa saber relacionar-se e trabalhar com a comunicação não-verbal, em que palavras são, às vezes, substituídas por comportamentos e atitudes ${ }^{(17)}$. O enfermeiro que cuida em Unidades Oncológicas e de Terapia Intensiva necessita ter em mente que o cuidado é uma atitude inerente ao ser humano e, portanto, o ser enfermeiro deve apropriar-se do cuidar em sua prática profissional.

Neste estudo, alguns enfermeiros se posicionaram de maneira contrária possibilitando a formulação da seguinte categoria: distanciamento na assistência profissional, afirmando em suas falas que o envolvimento afetivo e emocional e até mesmo religioso pode ser antiético e até trazer danos à prestação da assistência adequada à relação Paciente-Enfermeiro-Família. Estes acreditam que para desempenhar bem sua prática profissional nas unidades devem se manter distantes, evitando construir vínculos de afeto, carinho e amizade com os pacientes e familiares, para evitar o sofrimento em situações de morte, como expressado na fala abaixo:

Assim, você tem que manter uma certa distância [...], isso não quer dizer que você não vai prestar uma assistência de qualidade para o paciente, mas você tem que entrar em um distanciamento, para não entrar em depressão toda vez que um paciente morre. (Enf. 2- UTI). 
O enfermeiro de UTI, associa a postura profissional de competência e qualidade elevada ao distanciamento e prefere um perfil rígido, frio, inflexível e tecnicista na assistência da equipe de enfermagem ${ }^{(3)}$. Atitudes capazes de gerar o campo representacional do enfermeiro em suas práticas cotidianas verificadas neste estudo evidenciam a compreensão equivocada da necessidade de separação dos conceitos apresentados para a vida pessoal em face da conduta profissional, valorizando o uso de procedimentos técnicos e tecnológicos no cuidar em detrimento de metodologias holísticas e integrais no encontro com o outro que também envolvem os aspectos religiosos ${ }^{(8)}$, pois todos esses elementos biopsicossociais fazem parte do fenômeno cognitivo que permite compreender as representações sociais ${ }^{(15)}$.

\section{Representações do enfermeiro sobre os mecanismos} de enfrentamento do processo de morte.

Alguns enfermeiros afirmam que a maior dificuldade diante do processo da morte é a falta de preparo para lidar com ela, e acreditam na Capacitação e Aperfeiçoamento para a superação dessa dificuldade. A citada categoria revela a busca pelo conhecimento como instrumento de renovação do processo de cuidar e ainda como mecanismo de enfrentamento do processo de morte, como refere a fala abaixo:

Eu busco assim, pensar que eu estou fazendo o melhor possível para o paciente, para o serviço e para a instituição[...] (Enf. 13 - Oncologia).

O profissional comprometido a cuidar de pacientes em processo de morte em oncologia ou pacientes graves em UTI prepara-se para enfrentar situações de sofrimento e de morte na perspectiva da Tanatologia, ou seja, da educação para a morte ${ }^{(18)}$. Contudo, até então, a maior parte das instituições de ensino de enfermagem ainda não integrou a concepção tanatológica ao perfil curricular dos cursos $^{(12)}$. Aconselha-se que as representações que surgem diante desse processo sejam compreendidas e analisadas, pois estas advêm da insuficiência da ciência e da desinformação relativas à morte. A mudança de atitude almeja resultar na reflexão e discussão holística do tema em questão ${ }^{(8)}$.

O Conforto Espiritual e o Controle Emocional também aparecem como mecanismos de defesa e enfrentamento para cuidar do paciente em processo de morte. Nesta categoria, os enfermeiros evidenciam a religiosidade como elemento organizador da prática em benefício do paciente e para o profissional, que convergem para um equilíbrio entre o envolvimento afetivo e o distanciamento, a fim de evitar o sofrimento excessivo. Esses mecanismos estão presentes na seguinte fala:

[...] eu, pelo menos tento trabalhar a minha parte sentimental [...], mas, por outro lado, também não chega ao ponto de me envolver o suficiente, assim a deprimir, a sofrer, [...] é tipo um mecanismozinho de defesa, cada um utiliza o seu. (Enf. 11-Oncologia).

Os enfermeiros têm criado mecanismos de defesa que os auxiliam no enfrentamento do processo de morte ${ }^{(17)}$, sabe-se que a enfermagem está entre as profissões mais sujeitas aos agravos psíquicos e somáticos, geniturinários e osteomusculares, devido à natureza de sua rotina ocupacional, sobretudo devido à aproximação com a dor e a morte maior do que o resto da população ${ }^{(19)}$.

\section{E. Representações e experiências do enfermeiro frente ao processo de morte.}

A análise revela características próprias do contexto do grupo em estudo, no que se refere à teoria das representações sociais, isto é, as concepções são estruturantes das práticas, e estas, por sua vez, determinadas pelo sistema de representações, sendo, portanto, assumidas como um guia para as práticas, definindo o que é lícito ou inaceitável em determinado contexto social ${ }^{(20)}$.

Frente ao processo de morte, alguns enfermeiros referiram desempenhar suas atividades com Tranquilidade e Calma, ou seja, expressam sentimentos positivos que promovem crescimento e desenvolvimento a nível pessoal e profissional. Essa categoria revela que quando a representação do processo de morte remete ao equilíbrio da dinâmica biopsicossocial, então as experiências da vivência são pouco traumáticas para o profissional, sobretudo em oncologia, onde a morte é vivenciada, como revelam as falas abaixo:

Com tranquilidade, né?! Creio que morreu procuro me policiar de fazer comentários ruins. (Enf. 20-Oncologia).

Extremamente calma, viu?! Calma! Não tem estresse nenhum, eu tento acalmar a família, se a família fica estressada, fica aquele "auê" aqui, mas faço direitinho. (Enf. 14- Oncologia).

A calma e a tranquilidade são adquiridas com a experiência pessoal e a elaboração de mecanismos de enfrentamento, sobretudo religiosos. Em vista disso, todos os enfermeiros da pesquisa professaram uma religião e referiram participar de eventos religiosos com frequência. Essa estrutura psíquica elaborada a partir das representações da religiosidade no cuidar do paciente em processo de morte constrói-se como estruturante da prática ${ }^{(8)}$. Entretanto, alguns enfermeiros revelam que as vivências profissionais remetem ao sofrimento, frustração e impotência diante da morte. Assim a categoria Frustração e Sofrimento fundamenta-se nas falas:

Eles pedem assim para não morrer aí isso aí frustra você demais! '- Tia, não me deixe morrer!', eles morrem realmente com a plena consciência e isso é mais frustrante [...]. (Enf. 9- Oncologia).

[...] às vezes é muito frustrante por você achar que ia sair, que ia se recuperar, que ia ter possibilidade de se recuperar. (Enf. 5- UTI).

Diante das falas, reafirma-se que a morte ainda tem sido vista como um tabu para a sociedade atual. A realidade em que se encontra o enfermeiro no seu ambiente de trabalho, o sentimento de frustração diante da morte e a natureza religiosa no seio dessa representação, apontam para a importância 
de realizar-se estudos sobre a religiosidade relacionados aos objetos que compõe essa realidade social ${ }^{(19)}$.

Ainda mostra-se importante referir neste estudo que as representações sociais dos enfermeiros acerca do processo de morte estão relacionadas à compreensão do ciclo de vida que fundamenta as vivências, por exemplo, a morte de idosos e adultos em estado de saúde grave ou comprometidos, sendo este um fato aceitável para o profissional. Contraditoriamente, a morte de crianças caracteriza-se como um fato impactante que causa angústia e sofrimento, como evidenciado na seguinte fala:

Morte de criança é mais difícil para mim, porque a gente sempre imagina que ela tinha todo um futuro pela frente, tem uma perspectiva, tinha um plano. (Enf. 8- Oncologia).

Outra relação que remete ao sofrimento e a frustração do enfermeiro, além da morte da criança, diz respeito à morte de um paciente próximo, com presença marcante e frequente no serviço, seja por tempo de internamento, seja por identificação com a equipe, como na fala abaixo:

Tem paciente que a gente se pega mais, e sofre mais quando morre, tem paciente mesmo aqui que eu não vou querer estar aqui quando morrer, [...].. (Enf. 10 - Oncologia).

As representações acerca da morte são elaboradas para a enfermagem bem como para a sociedade, fundamentadas nas concepções religiosas. A religião emerge dessas experiências quando vivenciadas no coletivo, sentimentos de sofrimento e a maneira de enfrentar a morte, depende do sentido que é dado por cada um, suas crenças, religião e ou mesmo de sua religiosidade. A partir daí são observadas expressões no cuidar e no relacionamento do enfermeiro com o paciente e a família, frente ao processo de morte como demonstra este estudo.

A apreensão da religiosidade no processo de morte está atrelada a realidade social e vivência dos profissionais acerca da morte, e às questões pessoais e profissionais no contexto em que se encontram. É importante estar informado sobre o que acontece no mundo a nossa volta, saber se relacionar, comportar-se, identificar e resolver as situações que se apresentam e é por isso que se cria representações ${ }^{(8)}$.

\section{CONSIDERAÇÕES FINAIS}

O presente estudo possibilitou desvelar as representações de um grupo de enfermeiros de Oncologia e UTI sobre o processo de morte, revelando tanto os significados quanto o caráter simbólico da religiosidade ao cuidar de pacientes, bem com os elementos do fenômeno cognitivo que permitem compreender as representações sociais relativas à contribuição das experiências vividas por eles sobre a religiosidade nesse processo. Além disso, foi possível refletir sobre os conceitos que determinam o comportamento, de modo a permitir ao enfermeiro elaborar mecanismos de enfrentamento, revelando medos e crenças ao inserir a religiosidade como instrumento terapêutico em benefício de quem cuida e de quem é cuidado.

A análise das falas permitiu revelar que os enfermeiros compreendam o processo de morte inserindo suas concepções religiosas, conceituando a morte em alguns momentos como sendo uma passagem, remetendo à representação simbólica de um caminho para o conforto e alívio do sofrimento. O enfermeiro ainda realiza preces e orações ao cuidar, o que demonstra que respeitando e incentivando a religiosidade do paciente e da família é possível ser um profissional capaz de promover o acolhimento e a humanização. Contudo, algumas falas evidenciam o distanciamento na assistência como mecanismo de enfrentamento.

Com este estudo propõe-se a inserção da temática no perfil curricular de graduação em enfermagem. Tendo sido verificada a necessidade de capacitação em grande parte das falas, constatou-se que a mesma precisa funcionar como elemento norteador da prática, favorecendo a aprendizagem do autocuidado pelo profissional, diminuindo o risco de doenças decorrentes da rotina de trabalho, e oferecendo suporte psicológico e educacional dentro dos serviços, o que contribuiria positivamente para a desmistificação da representação da postura profissional distanciada.

Consideram-se ainda as representações sociais dos enfermeiros, acerca da religiosidade ao cuidar do paciente em processo de morte, como extremamente relevantes, e que necessitam serem compreendidas no cotidiano profissional, visto que o trabalho apreendido pelo enfermeiro no campo das representações sociais implica na análise da realidade, na tomada de consciência e então na mudança de atitude.

\section{REFERÊNCIAS}

1. Barros ASD, Martins CRM. A percepção do técnico de enfermagem sobre sua formação em Tanatologia. Rev Psicol UNESP. 2009;8(1):125-38.

2. Santos RL, Ojeda BS, Gerhart LM, Eidt OR, Stein SC, Mello DT. Nexos e desafios na formação profissional do enfermeiro. Rev Bras Enferm. 2010;63(4):555-60.

3. Shimizu HE. Como os trabalhadores de enfermagem enfrentam o processo de morrer. Rev Bras Enferm. 2007; 60(3):257-62.
4. Pereira LA, Thofehrn MB, Amestoy SC. A vivência de enfermeiras na iminência da própria morte. Rev Gaúch Enferm. 2008;29(4):536-42.

5. Bousso RS, Polis K, Serafim TS, Miranda MG. Crenças religiosas, doença e morte: perspectiva da família na experiência de doença. Rev Esc Enferm USP. [periódico na internet]. 2011 [acesso em 3 maio 2013];45(2):397-403. Disponível em: http://www.scielo.br/pdf/reeusp/v45n2/ v45n2a13.pdf. 
6. Lima VR, Buys R. Educação para a morte na formação de profissionais de Saúde. Arq Bras Psicol. 2008;60(3):342-69.

7. Kubler-Ross E. A roda da vida: memórias do viver e do morrer. 2. ed. Rio de Janeiro: Sextante; 1998.

8. Jodelet D. As representações sociais. Rio de Janeiro: Eduerj; 2001. p.17-44.

9. Bardin L. Análise de Conteúdo procedimentos metodológicos. 70. ed. Lisboa: Edições 70; 2007.

10. Campana H, Domingos A, Sanches $P$, Correa D. A percepção dos mestrandos de enfermagem a respeito da religião como recurso terapêutico no processo de recuperação do ser humano doente e sua família. Cogitare Enferm [periódico na internet]. 2009 [acesso em 10 jun 2010];2(3):119- 28. Disponível em: http://ojs.c3sl.ufpr.br/ ojs2/index.php/cogitare/article/view/11950/8432.

11. Araujo FP, Ferreira MA. Representações sociais sobre humanização do cuidado implicações éticas e morais. Rev Bras Enferm [periódico na internet] 2011 [acesso em 7 mar 2012];64(2):287-93. Disponível em: http://www.scielo.br/pdf/reben/v64n3/v64n2a17.pdf.

12. Oliveira JRD, Brêtas JRDS, Yamaguti L. A morte e o morrer segundo representações de estudantes de enfermagem. Rev Esc Enferm USP. [periódico na internet]. 2007 [acesso em 14 ago 2010];41(3):213-25. Disponível em: http://www.scielo.br/pdf/reeusp/v41n3/07.pdf.

13. Rito AMR, Brito MJM, Gazzinelli MFC, Montenegro LC. Representações sociais de discentes de graduação em enfermagem sobre "ser enfermeiro". Rev Bras Enferm [periódico na internet]. 2011 [acesso 25 mar 2012];64(3):52735. Disponível em: http://www.scielo.br/pdf/reben/ v64n3/v64n3a17.pdf.

14. Horta M. Eutanásia: problemas éticos da morte e do morrer. Rev Bioét [periódico na internet]. 2009 [acesso em 27 set 2012];(1):89-114. Disponível em: http://revistabioetica.cfm.org.br/index.php/revista_bioetica/article/ view/290/429.

15. Gomes TO, Almeida Filho AJ, Baptista SDS. Enfermeiras religiosas na luta por espaço no campo de Enfermagem. Rev Bras Enferm. 2005;58(3):238-57.

16. Bousso RS, Serafim TS, Misko MD. Histórias de vida de familiares de crianças com doenças graves: relação entre religião, doença e morte. Rev latino-Am Enferm. [periódico na internet]. 2010 [acesso em 3 maio 2013];18(2):123-40. Disponível em: http://www.scielo.br/pdf/rlae/v18n2/pt_03.pdf.

17. Pinho LMO, Barbosa M. The professor-student relationship in coping with dying. Rev Esc Enferm USP [periódico na internet]. 2010 [acesso em 25 mar 2012];44(1):10712. Disponível em: http://www.scielo.br/pdf/reeusp/ v44n1/en_a15v44n1.pdf.

18. Kovács MJ. Morte e desenvolvimento humano. 3. ed. São Paulo: Casa do Psicólogo; 1992. p.134.

19. Nascimento AMD, Roazzi A. A estrutura da representação social da morte na interface com as religiosidades em equipes multiprofissionais de saúde. Psicol Reflex Crit. [periódico na internet]. 2007 [acesso em 12 abr 2012];20(3):307-12. Disponível em: http://www.scielo. br/pdf/prc/v20n3/a11v20n3.pdf.

20. Abric J. O estudo experimental das representações sociais. In: Jodelet D, organizadora. As representações sociais. Rio de Janeiro: Universidade Federal do Rio de Janeiro; 2002. p. 15-52. 